\title{
What does society expect of veterinarians?
} David Wilkins

\author{
Address: World Society for the Protection of Animals, London, SE1 7TP, UK \\ Email: David Wilkins - wilkinsvet@btinternet.com
}

\begin{abstract}
from The role of the veterinarian in animal welfare. Animal welfare: too much or too little? The 2 Ist Symposium of the Nordic Committee for Veterinary Scientific Cooperation (NKVet)

Værløse, Denmark. 24-25 September 2007

Published: 19 August 2008

Acta Veterinaria Scandinavica 2008, 50(SuppI I):S3 doi:I0.I I86/I75I-0I47-50-SI-S3
\end{abstract}

This abstract is available from: http://www.actavetscand.com/content/50/SI/S3

(c) 2008 Wilkins; licensee BioMed Central Ltd.

\section{Introduction}

What society expects and how veterinarians respond does not necessarily correspond. The vast majority of people look upon veterinarians as people who will cure their animal when it is ill, repair traumatic injuries and advise on its general well being.

Veterinarians are well-respected members of the community and whilst their animal health role is recognised it is sometimes not so clear as to their animal welfare role. Veterinarians are one of many stakeholders with an interest in animal welfare and in many instances can get shouldered aside. Nevertheless they are uniquely placed to be the "animals advocate" and should, in most circumstances play a leadership role. It is a matter of regret to me that this does not necessarily happen.

\section{Local level}

Veterinarians in general practice should take a more active role in the local community. They should use the trust and respect that they have from the general public to make a larger contribution than they do. Educations in responsible pet ownership, advising the local authority on pets in old people's care homes and on the policy that hospitals should adopt towards animals. I have seen many badly advised local politicians and community health workers making decisions about animals that are detrimental to both the animals and their owners. Veterinarians should take a more proactive role and I believe that they have a responsibility to do so. Whilst I was in practise, many years ago, I was elected as a councillor on my local district (government) council. It was the first time that a vet had been elected and I was able to have a positive influence in many areas. To do such work does not mean that you have to become a "politician" in the sense of belonging to a political party. I stood as an independent and in local politics I believe that it is still possible. Not so, perhaps, at higher levels of government.

Another area in which I think veterinarians should become more involved is in courts of law. In the UK, for example, only a veterinarian can give an opinion in a case involving animal cruelty. He or she is an expert witness. Giving evidence in a court of law can be daunting particularly if the case is being strongly defended with a veterinarian on the other side. But, again, I believe veterinarians have a duty to give evidence on behalf of the prosecution if they have examined the animal(s) involved and are clear in their opinion. If approached by a defendant and they strongly believe that the case is based on inaccurate or false scientific evidence then they should be willing to appear in court.

I believe that many veterinary schools now provide students with a chance to study forensic medicine and become familiar with the task of giving evidence.

\section{Regional/national level}

To become involved in politics at a regional or national level is more challenging and can be more time consuming but the veterinary profession should and could do more. By and large politicians and civil servants trust them. They are in a position to provide independent veterinary opinions that can influence the policy makers. In 
some countries advice to governments is given through an advisory body. In the UK for example, it would be the Farm Animal Council. In Denmark, I believe you have an Ethical Advisory Body. Veterinarians will be members of such advisory groups but with other stakeholders. However I think it is important that more proactive efforts are made to ensure that policy formers and politicians receive the best possible scientific information and advice.

A classic example of a veterinarian who had a significant influence on political decisions was a UK vet - the late Don Haxby. A man of the highest integrity and who, through expert knowledge and great experience, an affable and generous nature and an ability to get on with people from all walks of life and political persuasions, made himself indispensable as a veterinary adviser to the UK Parliament. However he did not wait for the politicians to come to him, he made sure that they knew he was available. His greatest strength and this is a very important point to remember if you are involved in political lobbying, was that he made sure that the briefing he gave to politicians was factually correct. Giving a politician a false briefing will come back to haunt you and you may not be trusted a second time. Of course you are entitled to express an opinion but make sure that your listener knows it is an opinion.

\section{International level}

We now come to look at what the veterinary profession is doing at international level.

I worked in Brussels on behalf of animal welfare organisations for over 20 years and for all but the last few years an organised and effective veterinary input into the debate on European animal welfare legislation was conspicuous by its absence. Some comment came from the odd individual rather than an organised veterinary lobby. This was also the case in the Council of Europe when the veterinary representative had to make interventions based on a personal belief rather than one following consultation with colleagues. The Federation of Veterinarians in Europe (FVE) was an official observer organisation to the Council of Europe but the consultation process within that organisation was a shambles and the veterinarian who was sent to Strasbourg to represent the FVE had to make do as best he could.

I am delighted that now the FVE plays an influential role in shaping many European laws whether they are concerned with animal health, professional qualifications, veterinary medicines or animal welfare. This has been the case for the last few years following a decision to have a properly staffed office in Brussels and the approach is now professional and effective. I believe that the transformation should have happened earlier. The organisation that
I headed - Eurogroup for Animal Welfare - was professional from its foundation in 1980 . It provided the European Institutions - Commission, Parliament and Council - with informed, scientifically based, comment and opinion. In return it achieved a reputation for credibility, expertise and availability. That I was a veterinarian was of great assistance in briefing Members of the European Parliament and we exerted great influence. I am still convinced that if the FVE was playing as strong a role then as it does now then the animals would have been better served.

There are many examples around the world where the veterinary profession is failing to make its presence felt and its expert knowledge known.

I do not know whether it is a lack of belief in ones own ability to influence the political scene or a reluctance to become involved in the maelstrom that is political life, but too few of us want to play a political role.

It is worth repeating that if you become a political lobbyist as I did then you have to build up trust. In the European Union this trust has to be between you and Commission officials, Members of the European Parliament and also with representatives from Member States. Never invent facts to fit what you may think the politician wants to say. Offer opinions when invited but always make it clear that these are opinions. It is also important to keep briefings simple. Most MEPs are not technically minded and have little time to read complicated scientific papers.

\section{Global level}

In many parts of the world veterinary advice can literally mean the difference between life and death not only for animals but for humans too. About a billion of the world's poorest people depend on animals for food, income, social status or cultural identification, as well as companionship and security. To them, losing animals from disease or natural disasters is a catastrophe. It is easy to understand why small "backyard" poultry farmers in many countries, particularly in South-east Asia, do not report sick birds to the authorities even during an outbreak of avian flu. No compensation is offered for slaughtered birds so any sick bird is killed and cooked for food as quickly as possible. Veterinary control measures are difficult to apply in practice but if a disease destroys most of those small farmer's poultry or if they are slaughtered compulsorily then those dependant on the poultry will suffer severe hardship. In such circumstances veterinarians must work with compassion as well as efficiently and must also be prepared to argue with government departments when necessary. Of course in most of these examples it is the State Veterinary Service that leads the fight against notifiable diseases. Large-scale disease outbreaks 
are amongst the most serious of disasters, having the potential to kill millions of animals and, in some cases, many people and to devastate the economies of local communities and entire countries.

Official Veterinary Services have a vital role to play trying to prevent or control these diseases but could they do more? Achieving good animal health standards is essential but promoting animal welfare is also important. In the latter case many chief veterinary officers do not appear to take their welfare responsibilities very seriously. Such a situation existed in Europe some 40 years ago but times and vets have changed, at least in most European countries.

The organisation that I now work for, the World Society for the Protection of Animals (WSPA) has been involved in helping animals in the aftermath of natural and manmade disasters. We are not a wealthy organisation but we do have over 800 member organisations in 147 countries so we are ideally placed to play a co-ordinating role in the rescue operation. In all these rescue activities the veterinarian is essential. However in many instances more could have been done to reduce the risks. In many parts of the world floods, earthquakes, hurricanes or volcanoes erupting are regular occurrences. Good contingency planning is essential. In disaster risk management it is important that animal health and welfare is considered along with human health and welfare. It should be the role of the veterinarian to ensure that this is done.

WSPA is presently working with other global organisations, WHO, UNESCO, FAO and humanitarian agencies to produce a factual manual of what can be done to limit the terrible loss of lives (humans and animals) following disasters. The veterinary input came from the World Organisation for Animal Health (OIE). Some of you will know that in 2001 the OIE decided to enlarge its responsibilities and to begin to formulate international animal welfare standards. This was a significant step and there is no doubt it has had a major impact in raising the awareness of the importance of animal welfare around the world.

Some disasters are man made. For example, in the Darfur region of Sudan there is a massive refugee problem. Many of these refugees bring their animals with them, a couple of goats, some poultry, maybe a cow. These animals represent survival for the owners. Therefore as well as catering for the humans in these refugee camps provision must be made for the animals. What food, medicines and other essentials are provided should be the decision of veterinarians. Sometimes authorities and humanitarian agencies are slow to recognise this. When Hurricane Katrina devastated New Orleans those rescuing people from flooded houses were surprised when they refused to leave without their pet animal. They should not have been as any veterinarian is aware of the strong human-animal bond and could, if consulted, have told them. Furthermore when these people, plus their pets, arrived at the place of refuge no provision had been made for coping with the animals. It needed a veterinary input at the planning contingency stage. Perhaps vets were not asked but they should have come forward.

\section{Conclusion}

As a profession we should be more aware of the good we can do on the larger stage. Our expertise in curing the sick or injured animal will always be in demand but our knowledge of the welfare of animals and their needs is also unique and we should not be reticent in coming forward. Society expects veterinarians to be involved wherever animals are at risk or are about to be placed at risk. We must never be complacent and assume that someone will ask for veterinary advice when it is required. It does not always happen so we must be more pro-active, ask more questions and make sure that everyone knows that we are there and willing to be involved. 